\title{
RESISTANCE IN MAIZE TO THE TROPICAL AMERICAN RUST FUNGUS, PUCCINIA POLYSORA
}

\author{
II. LINKAGE OF GENES Rpp $\mathbf{R p}_{1}$ AND $\mathbf{R p p}_{2}$
}

H. H. STOREY and AUDRIE K. HOWLAND

East African Agriculture and Forestry Research Organisation

Received 5.v.58

IN this paper we report studies of the genetic relationships of two genes in maize known to confer resistance to the tropical rust fungus, Puccinia polysora Underw. (Storey and Howland, I957). The work was done at the East African Agriculture and Forestry Research Organisation at Muguga, Kenya. We owe much to Sir Joseph Hutchinson, F.R.s., for advice on interpretation and to $\mathrm{Mr} \mathrm{J}$. T. Walker for assistance in statistical estimations.

\section{MATERIAL AND METHODS \\ (i) Experimental methods}

Methods for inoculating young maize seedlings with uredospore suspensions remained unaltered (Storey and Howland, loc. cit.), except that in most experiments we inoculated the two rust races, EA.I and EA.2, simultaneously to separate leaves of each seedling. Consequently phenotypes are defined in the form-

Reaction to EA.I/Reaction to EA.2.

Rust reactions were scored qualitatively as in our earlier work; but on the evidence there given they can be grouped in four classes :-

Class "or "-Previously "o I, sub-class (a)"; characteristic reaction of $\mathbf{R}_{\mathbf{1}}$ * against EA.r.

Class "I "-Previously the range from "oI $(b)$ " to " $\mathrm{I}++$ "; reaction of $R_{2}$ to EA.I and EA.2.

Class "X"-Indeterminate class between " I " and " 4 ", believed to indicate $\mathbf{R}_{2}$ in combination with unfavourable minor genes.

Class " 4 "- -Susceptible reaction of recessive genotypes; also of $R_{1}$ against EA.2.

\section{(ii) Sources of resistance genes}

Pure lines, derived from the three American introductions already studied (Storey and Howland, loc. cit.) and designated by their introduction numbers, were used.
AFRO.29. Gene $R_{1}$. Reaction "o $1 / 4$ ".
AFRO.24. Gene $R_{2}$. Reaction " $I / I$ ".
AFRO.27. Gene $R_{2}$ (?) Reaction " $\mathrm{I}-\mathrm{X} / \mathrm{i}-\mathrm{X}$ ”.

Two African lines, that had reacted " $4 / 4$ " in many tests, provided doublerecessive genotypes.

\section{RESISTANCE GENES OF AFRO.29 AND AFRO.24}

Five families, from crosses of AFRO.29 and AFRO.24, inoculated with Rust Race EA.I, all reacted " o " and were indistinguishable from plants carrying $\mathbf{R}_{\mathbf{1}}$ alone. Inoculated with EA.2, they reacted

* The gene designations $\mathrm{Rpp}_{1}$ and $\mathrm{Rpp}_{2}$ are shortened to $\mathrm{R}_{1}$ and $\mathrm{R}_{2}$ in this paper. 
in the severe range of "I" and were indistinguishable from the heterozygote carrying $\mathbf{R}_{2}$ alone (table $\mathbf{~}$, series $A$ ).

Backcrossing the $F_{1}$ to the double recessive gave the eight families in table $\mathrm{I}$, series $\mathrm{B}$, which segregated into the four phenotypes shown at the head of the table. Segregation evidently differed from that expected on independent assortment of genes. Analysis showed that segregation of $\mathbf{R}_{1}, \mathbf{r}_{1}$ and $\mathbf{R}_{2}, \mathbf{r}_{2}$, did not deviate significantly from I : I ratios; but the $\chi^{2}$ component for linkage was highly significant. The individual eight families (not recorded separately in the table) gave no evidence of heterogeneity.

TABLE I

Crosses involving AFRO.29 $\left(\mathbf{R}_{1}\right)$ and AFRO.24 $\left(\mathbf{R}_{2}\right)$

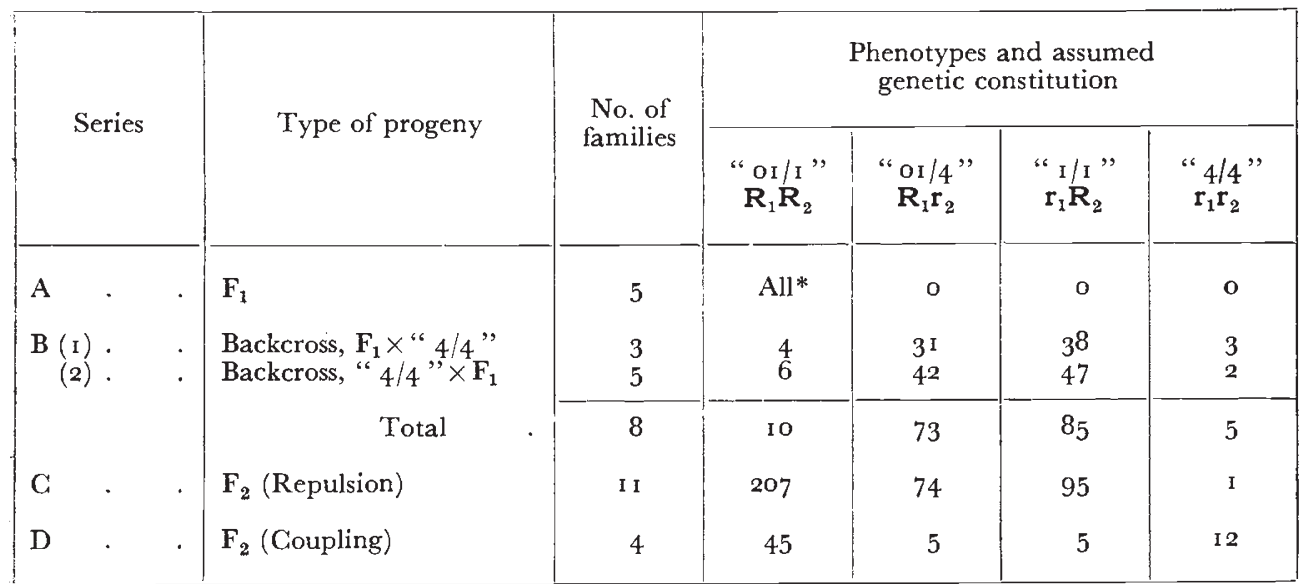

* In individual tests, $48 \mathrm{~F}_{1}$ plants were all " or " against EA. I ; and 96 were " I " against EA.2.

The reciprocal crosses did not differ significantly one from the other. Gametic segregation appeared therefore to be identical in each sex.

$\mathrm{F}_{2}$ families were raised by selfing $\mathrm{F}_{1}$ plants. Total numbers of the four phenotypes obtained in eleven families are recorded in table $\mathrm{I}$, series C. A single " $4 / 4$ " plant appeared in a total of 377 ; this plant was further studied, (a) by reinoculation, when the " $4 / 4$ " classification was again observed, and $(b)$ by selfing, which gave an entirely " $4 / 4$ " family (26 plants). This plant was therefore the double-recessive recombinant $\left(r_{1} r_{2}\right)\left(r_{1} r_{2}\right)$.

Of these $F_{2}$ totals, the $R_{1}, r_{1}$ segregation did not deviate significantly from a 3 : I ratio and the eleven families constituted a homogeneous group. In the $\mathbf{R}_{2}, \mathbf{r}_{2}$ segregation there was a just significant shortage of $r_{2}$ genotypes ( $P$ lying between 0.02 and 0.05 ); and in this regard also the families were homogeneous, ten of the eleven contributing to the shortage of $r_{2}$, although in only one of these did the individual departure reach significance. Despite this disturbance in one-factor segregation, there is still a large $\chi^{2}$ for joint segregation, indicating linkage in the repulsion phase. 
No explanation is evident for the deviation in the $\mathbf{R}_{2}, \mathbf{r}_{2}$ segregation in this generation. It is improbable that $\mathbf{r}_{2}$ genotypes can have been classed "I" in error (although the converse can occur, as we show in the next section). There was no suggestion of lowered viability in any of the eleven families; the ears were uniformly filled and failures in germination were few and appeared to be due to fungus infection. It is to be noted that in the backcrosses also there was a suggestion of shortage of $\mathbf{r}_{2}$ genotypes, but not reaching significant level.

By selfing " or/I " phenotypes selected from the backcross families, we bred the four $\mathrm{F}_{2}$ families recorded as series $\mathrm{D}$ in table $\mathrm{I}$. Individual segregations of the two gene pairs conformed very closely to $3: \mathrm{I}$ ratios and there was here no indication of any departure of $\mathbf{R}_{2}, \mathbf{r}_{\mathbf{2}}$

TABLE 2

Selfs of " $\mathrm{OI} / \mathrm{I}$ " phenotypes selected from the coupling $F_{2}$ families, series $D$ of table $I$

\begin{tabular}{|c|c|c|c|c|c|c|c|}
\hline \multirow{2}{*}{ Group } & \multirow{2}{*}{$\begin{array}{c}\text { Probable genotype } \\
\text { of parents }\end{array}$} & \multirow{2}{*}{$\begin{array}{l}\text { Numbers of families } \\
\text { expected at } 12 \cdot 23 \% \\
\text { recombination }\end{array}$} & \multirow{2}{*}{$\begin{array}{l}\text { Observed } \\
\text { numbers } \\
\text { of families }\end{array}$} & \multicolumn{4}{|c|}{ Numbers of phenotypes observed } \\
\hline & & & & "OI/I" & "O $/ 4 "$ & “I/I" & $" 4 / 4 "$ \\
\hline I & $\left(\mathbf{R}_{\mathbf{1}} \mathbf{R}_{2}\right)\left(\mathbf{R}_{\mathbf{1}} \mathbf{R}_{\mathbf{2}}\right)$ & $5 . \mathrm{OI}$ & 3 & $5^{6}$ & 0 & 0 & 0 \\
\hline 2 & $\left(\mathbf{R}_{1} \mathbf{R}_{2}\right)\left(\mathbf{r}_{1} \mathbf{r}_{2}\right)$ & IO.OI & I 2 & I I 9 & IO & I 4 & $3^{I}$ \\
\hline 3 & $\left(\mathbf{R}_{1} \mathbf{R}_{2}\right)\left(\mathbf{R}_{1} \mathbf{r}_{2}\right)$ & I 39 & 0 & $\cdots$ & $\cdots$ & $\cdots$ & $\cdots$ \\
\hline 4 & $\left(R_{1} R_{2}\right)\left(r_{1} R_{2}\right)$ & I 39 & 2 & $4^{I}$ & o & 12 & $\mathbf{o}$ \\
\hline 5 & $\left(R_{1} r_{2}\right) \quad\left(r_{1} R_{2}\right)$ & O'I 9 & I & 7 & 2 & 3 & o \\
\hline
\end{tabular}

from this ratio. The four families constituted a homogeneous group. The recorded segregation gave strong evidence of linkage in the coupling phase, which accords with the expected genotype $\left(\mathbf{R}_{\mathbf{1}} \mathbf{R}_{\mathbf{2}}\right)$ $\left(\mathbf{r}_{1} \mathbf{r}_{2}\right)$ of the parents.

Eighteen $\mathrm{F}_{3}$ families were raised by selfing selected " o I/I " phenotypes from the coupling $F_{2}$ of the previous paragraph. There are five possible double-dominant genotypes that could occur, each giving, on the assumption of linkage, a characteristic segregation in its selfed progeny. On this basis the eighteen families have been grouped as shown in table 2. The expected numbers of families in each group, on a recombination fraction of 12.23 per cent. (see below), appear in the third column of the table. The observed numbers appear not to deviate significantly from these expectations.

The twelve families in group 2 are believed to derive from $\left(\mathbf{R}_{\mathbf{1}} \mathbf{R}_{\mathbf{2}}\right)$ $\left(r_{1} r_{2}\right)$ and consequently provide further evidence on linkage in the coupling phase. The $\mathbf{R}_{1}, \mathbf{r}_{1}$ and $\mathbf{R}_{2}, \mathbf{r}_{2}$ segregations do not differ significantly from $3: \mathrm{I}$ and the twelve families are homogeneous; the evidence for linkage is strong.

Three families in group I were homozygous double-dominant recombinants and provided the material that was the practical objective of the breeding. 
On the assumption that gametic segregation is identical in the two sexes-which accords with the evidence of the backcrosses-values were estimated, by the method of maximum likelihood, of the recombination fraction for each of the sets of family totals, as follows :

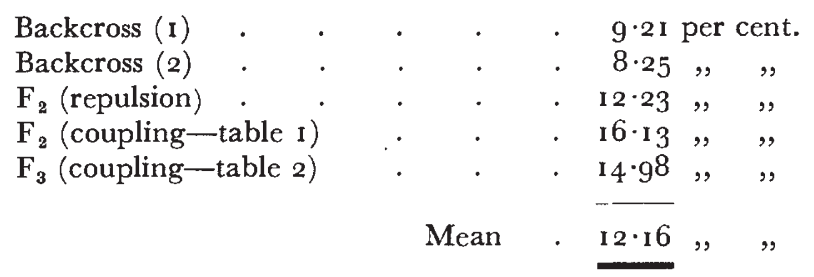

A combined estimation of the recombination fraction from the whole of the data provided the figure of 12.23 per cent., with a standard error of $\pm \mathrm{I} \cdot 60$ and confidence limits, at $P=0 \cdot 05$, of $9 \cdot 10$ and $I_{5} \cdot 37$ per cent.

The observed numbers in each of the five sets of families showed no significant deviation from the expectations calculated on this recombination fraction.

\section{THE RESISTANCE GENE OF AFRO.27}

We have suggested (Storey and Howland, loc. cit.) that AFRO.27 carries $\mathbf{R}_{2}$, but modified by minor genes to give phenotypes of generally lower resistance than those carrying $\mathbf{R}_{2}$ from AFRO.24. If this is true, the cross with AFRO.29 should exhibit linkage similar to that of AFRO.24 by AFRO.29.

The $F_{1}$, inoculated with EA.I reacted "or"; and, with EA.2, reacted mostly " $X$ " but with a scatter into grades of " I ". In addition, two plants out of 195 inoculated with EA.2 were classed " 4 ". One of these was selfed, and its progeny segregated, showing that the parent carried $\mathbf{R}_{2}$ and was not the double recessive suggested by its class " 4 " phenotype.

Eight backcross families were raised. In recording simultaneous tests against the two rust races, it was often difficult to decide between classes " X" and " 4 " for the EA.2 reaction. On the most favourable interpretation, by allocating all doubtful classifications to " $\mathrm{X}$ ", the segregation was as follows:-

\begin{tabular}{|c|c|c|c|c|}
\hline & "OI/I-X" & "or/4" & $" I-X / 1-X "$ & $" 4 / 4 "$ \\
\hline Observed . & 4 & $5^{6}$ & 27 & 20 \\
\hline $\begin{array}{l}\text { Expectation on i } 2 \cdot 23 \text { per cent. } \\
\text { recombination }\end{array}$ & $6 \cdot 54$ & $4^{6} \cdot 9^{6}$ & $4^{6 \cdot} \cdot 9^{6}$ & $6 \cdot 54$ \\
\hline
\end{tabular}

The apparent $R_{1}, r_{1}$ segregation is not under suspicion, but that of $R_{2}, r_{2}$ deviates significantly from a $\mathrm{I}:$ I ratio, the " 4 " class being in large excess. 
Five selected " $4 / 4$ " phenotypes were selfed. Only one gave a uniform " $4 / 4$ " progeny and was the double recessive. Four progenies segregated and their parents therefore carried $R_{2}$ despite their " $4 / 4$ " classification. There is therefore a further suggestion that minor genes from AFRO.27, and possibly from the susceptible parent of the backcross, may degrade an $\mathbf{R}_{\mathbf{2}}$ genotype to full susceptibility. Evidently the discrepancy in the $\mathrm{F}_{2}$ totals is mainly ascribable to misclassification of genotypes ; and if it be assumed that only one in five of the recorded " $4 / 4$ " phenotypes is the double-recessive genotype, the remaining four being properly classed with " I-X/I-X", the observed totals do not diverge widely from the expectation based on $12 \cdot 23$ per cent. recombination.

The identity of the resistance gene in AFRO.27 remains uncertain, but there is no conclusive evidence that it is not $\mathbf{R}_{\mathbf{2}}$.

\section{SUMMARY}

When pure lines carrying $\mathbf{R p p}_{1}$ and $\mathbf{R p p}_{2}$ (hereafter designated $R_{1}$ and $R_{2}$ ) were crossed, the progeny gave the characteristic reaction of the former if inoculated with the rust race EA.I and that characteristic of $\mathbf{R}_{2}$ if inoculated with EA.2. Backcrosses and repulsion and coupling $\mathrm{F}_{2}$ 's were classified by simultaneous inoculation of separate leaves of each seedling with the two rust races. Observed segregations showed that the two genes are linked, with a recombination fraction estimated at 12.23 per cent. and confidence limits $(\mathbf{P}=0.05)$ at 9.10 and 15.37 per cent.

From an $\mathrm{F}_{3}$ generation families were selected that were the pure double-dominant recombinant $\left(\mathbf{R}_{\mathbf{1}} \mathbf{R}_{\mathbf{2}}\right)\left(\mathbf{R}_{\mathbf{1}} \mathbf{R}_{\mathbf{2}}\right)$.

The $\mathbf{R}_{\mathbf{1}}$ line was also crossed with a second pure line believed to be carrying $\mathbf{R}_{2}$ but modified towards lowered resistance by minor genes. It was found that genotypes carrying this resistance gene might sometimes be modified to full susceptibility; but, if account were taken of this, the evidence did not disprove the supposed identity of the gene.

\section{REFERENCE}

STOREY, H. H., and HOWLAND, A. K. 1957. Resistance in Maize to the tropical American rust fungus, Puccinia polysora Underw. I. Genes $\mathrm{Rpp}_{1}$ AND $\mathrm{Rpp}_{2}$. Heredity, II, 289-30I. 